\title{
Max Weber ontem e hoje \\ Entrevista com Wolfgang Schluchter
}

\author{
Raquel Andrade Weiss* \\ https://orcid.org/0000-0002-5911-4147 \\ Tradução e apresentação de Carlos Augusto Silva Fabris* \\ https://orcid.org/0000-0003-2439-8618
}

Apresentação'

Considerado por muitos como um dos principais intérpretes da obra de Max Weber, Wolfgang Schluchter tem uma trajetória que se confunde com a da consolidação institucional da sociologia alemã e da importância contemporânea da obra weberiana. Suas contribuições teóricas ficam explicitadas em seus diversos livros publicados em torno dos seus comentários da obra de Weber, dando uma ênfase fundamental aos estudos comparados da religião e à narrativa da racionalização, propondo alternativas às leituras de outros intérpretes, como Talcott Parsons, e confrontando os escritos weberianos com as correntes sociológicas mais recentes. Além desses esforços teórico-sistemáticos autorais, Schluchter é um dos editores responsáveis pela publicação da coleção das obras completas de Max Weber, a Max-Weber-Gesamtausgabe (MWG).

Retomando esses aspectos, nesta entrevista, Schluchter realiza uma análise retrospectiva de sua trajetória profissional e intelectual, sendo uma pertinente sintetização de sua obra e de suas contribuições. Quando comparada com outras entrevistas²,

Universidade Federal do Rio Grande do Sul, Rio Grande do Sul, Brasil.

1. A presente entrevista foi realizada no ano de 2015, na cidade de Porto Alegre, no contexto do projeto "O Papel da Teoria Sociológica na Sociologia Contemporânea", coordenado por Raquel Weiss, com apoio do CNPq, Proex-Capes e Programa de Pós-Graduação em Sociologia. Uma versão resumida encontra-se disponível em vídeo no canal do projeto Talking Theory: https://youtu.be/t-fi7h0oZR8.

2. As demais entrevistas realizadas por Schluchter estão listadas nas referências. 
chama a atenção a consistência narrativa em que o autor mantém os principais elementos intocados, mesmo com um intervalo de tempo considerável (2004-2017). Destes, destacam-se as temáticas da sua própria biografia e a participação na edição da MWG, a questão das interpretações e traduções da obra de Weber, bem como a construção e a atualidade dos conceitos weberianos. No entanto, a presente entrevista diferencia-se das demais ao discutir outros tópicos pertinentes tanto para pensar a biografia pessoal de Weber, quanto para possibilitar um aprofundamento de seu aparato conceitual no sentido de refletir sobre os desafios contemporâneos, com destaque, nesta entrevista, para a secularização.

A trajetória de Schluchter e os primeiros contatos com a obra de Weber

Raquel Weiss [RW]: Olá, Professor Schluchter! É um imenso prazer tê-lo aqui, muito obrigada por participar desta conversa.

Wolfgang Schluchter [ws]: É um prazer estar aqui, e estou feliz por ter esta entrevista com você.

RW: Gostaria de começar perguntando sobre sua trajetória biográfica.

Ws: Eu nasci em 1938, no ano anterior ao começo da Segunda Guerra Mundial. Fui criado em uma família de professores: meu pai era professor e minha mãe era professora. Eu tinha três irmãos, então éramos quatro. Meu pai morreu na guerra, na Itália. Tenho algumas lembranças da Segunda Guerra Mundial, mas não muito marcantes. Então, depois da Segunda Guerra Mundial, minha mãe ficou sozinha com quatro crianças. Ela não casou de novo, então teve que nos criar sozinha. Foi muito trabalhoso, mas ela conseguiu dar uma boa educação para todos seus filhos, algo nada fácil nessa época, porque as coisas não eram comparáveis às de hoje. Era uma época muito difícil de sobreviver, de simplesmente sobreviver.

Minha verdadeira educação começou depois da Segunda Guerra Mundial e é muito conectada com o desenvolvimento da República Federal da Alemanha [Alemanha Ocidental]. Depois da reconstituição do país em 1949 com a constituição da República Federal da Alemanha, um novo desenvolvimento se iniciou, muito influenciado pelos Estados Unidos. E os Estados Unidos também eram como uma sociedade de referência para nós. A democracia era um modelo, e todos olhávamos para o outro lado do oceano nessa época.

Eu tive uma educação normal, passando pelo ensino médio alemão e depois tive a oportunidade de ir para a Universidade, onde consegui uma bolsa de estudos de 
uma famosa fundação alemã, que me permitiu estudar de acordo com meus próprios interesses. Comecei com literatura, filosofia e história, mas depois troquei para sociologia, economia e ciência política. Então tive um longo período de estudo nesses anos. Nós ainda éramos um número reduzido de jovens matriculados nas universidades. Só entre 5-6\% da nossa faixa etária entrou na universidade. Isso mudou; hoje nós temos 40 ou 45\%. Então, era uma situação que permitia bastante proximidade, nós conhecíamos uns aos outros, conhecíamos os professores e tínhamos uma comunicação bem intensa com eles. Aprender era o principal propósito. $\mathrm{O}$ ambiente em que me criei era um ambiente de aprendizado.

Eu tinha muitos interesses, principalmente na literatura, porque lia muito. Mas não sabia nada sobre sociologia. Naqueles tempos na Alemanha, a sociologia não era uma disciplina estabelecida. Foi introduzida mais tarde, com uma influência parcial dos Estados Unidos. Não se podia ter um diploma em Sociologia. Havia apenas duas instituições na Alemanha onde isso era possível, mas nem todas tinham esse tipo de programa educacional.

$\mathrm{RW}$ : Quando você descobriu a sociologia?

Ws: Curiosamente, descobri a sociologia por motivos práticos. Eu precisava ganhar algum dinheiro para minha própria sobrevivência e fiz parte de um programa para jovens que ensinavam jovens trabalhadores; lá encontrei a possibilidade de uma disciplina chamada sociologia. Como já estava um pouco insatisfeito com a literatura, decidi que provavelmente seria uma boa ideia mudar para a sociologia. A sociologia estava muito próxima da filosofia, e eu gostava muito de filosofia. Então decidi mudar. E isso foi feito após três ou quatro semestres, nos quais fiz principalmente literatura, história e filosofia, mudando para a sociologia e a economia. Sempre havia essa combinação de sociologia, economia e ciências políticas. E também mantive a filosofia por ora, até o final daquele semestre.

Mudei de universidade várias vezes e acabei em Berlim, na Universidade Livre de Berlim [Freie Universität Berlin] $]^{3}$. Lá se podia obter o diploma em sociologia, um dos poucos lugares na Alemanha onde isso era possível naquele momento, e então me tornei assistente de um professor de Sociologia e ficou claro que tentaria seguir essa disciplina. Acabou dando certo e me tornei sociólogo.

RW: Quando você se interessou pelo trabalho de Max Weber, foi antes ou depois de se tornar sociólogo?

3. Os trechos entre colchetes foram inseridos pelo tradutor. 
Ws: Foi depois. Comecei com uma tese sobre um constitucionalista alemão muito interessante e, na minha opinião, muito importante, chamado Hermann Heller. Ele foi uma das principais figuras da República de Weimar, lutando pela manutenção da República contra as forças de esquerda e direita que queriam destruí-la. Minha tese foi sobre Herman Heller e seus contemporâneos, comparando sua abordagem com a de Carl Schmitt e Rudolf Smend etc. E, nesse contexto, descobri Max Weber pela primeira vez, porque a teoria do Estado era bastante interessante para mim no contexto desse debate na República de Weimar. Este foi o meu primeiro livro, mais tarde chamado Decisão para o Estado Social de Direito [Entscheidung für den sozialen Rechtsstaat (1967)]. Heller cunhou este termo alemão: sozial Rechtstaat. Era um conceito muito importante para a reconstituição da República Federal da Alemanha; portanto, considero Heller uma figura muito importante. Infelizmente, ele não foi considerado por outros da mesma maneira. Outras pessoas que não apoiaram a República de Weimar ganharam mais reconhecimento após a Segunda Guerra Mundial do que Heller. Eu achei isso injusto, então tentei corrigir um pouco. Lá encontrei Weber pela primeira vez.

Então escrevi uma segunda tese, de habilitação [Aspekte bürokratisher Herrschaft: Studien zur Interpretation derfortschreitenden Industriegesellschaft (1972)]. Lá tentei comparar a tradição marxiana, por um lado, e a tradição saint-simoniana, por outro, com a teoria da burocracia de Max Weber. Portanto, já Weber ocupava o centro do palco como uma alternativa viável tanto à abordagem marxiana e à abordagem neomarxiana, quanto à abordagem saint-simoniana e neosaint-simoniana. Naqueles tempos, havia um grande debate entre a teoria crítica e as abordagens tecnocráticas. E tentei estabelecer uma terceira posição entre essas duas. Parte desse livro é uma interlocução muito séria com Herbert Marcuse, por exemplo, que se tornou muito famoso na década de 1960 na Alemanha, como uma espécie de líder intelectual do movimento estudantil, especialmente em Berlim, onde eu estava situado. Então eu também fazia parte desse movimento até certo ponto.

Nessa tese tratei de Weber a sério pela primeira vez. Tentei desenvolver sua teoria política também como uma alternativa para essas duas outras abordagens. Essa foi a segunda tese, necessária na Alemanha para obter uma cátedra. Naqueles tempos, deviam-se escrever duas monografias: uma era a tese normal, e a outra a habilitação, uma segunda tese. Esse foi o começo de meu sério interesse em Max Weber.

Nisso, no lado familiar, eu me casei, tivemos três filhos, e veio a chance de ir para os Estados Unidos, que foi crucial para mim. Eu estava ansioso por essa oportunidade. Passamos um ano em Pittsburgh, na Universidade de Pittsburgh na Pensilvânia, como bolsista Andrew Mellow de pós-doutorado. Então recebemos a oferta para ir a Singapura, onde me tornei professor sênior na Universidade de Singapura, que 
naquela época era a Universidade Britânica de Singapura. Naquele período, ainda havia uma separação entre a Universidade Britânica e a Universidade Chinesa, que mais tarde se fundiram; hoje existe apenas a Universidade de Singapura. Eu queria ser um professor sênior na Universidade de Singapura, o que foi um tremendo enriquecimento de nossas vidas, porque não apenas fomos para os Estados Unidos, mas também para partes da Ásia.

Era um mundo totalmente diferente do que experimentamos desde a juventude na Alemanha. Isso reforçou crucialmente meu interesse em Weber. Por quê? Porque Weber é o único sociólogo que tem um escopo de análise que abrange várias civilizações. Isso não se encontra em nenhum outro sociólogo, nem em Marx, nem em Durkheim, nem em Simmel, nem em Tönnies. Ninguém cobriu esse território.

Weber propôs um estudo comparativo das civilizações, e agora eu percebia a importância dos estudos comparativos na tradição sociológica. Estes eram em grande parte renegados pelo debate alemão naquela época. Apenas nos anos 1980 iniciei uma série de conferências internacionais sobre os estudos comparativos, no total seis conferências, com participação internacional, com pessoas da Índia, da China, dos Estados Unidos e assim por diante. O tema eram justamente estas questões: confucionismo, budismo, judaísmo antigo, cristianismo primitivo etc.

Então, essa parte do trabalho de Weber tornou-se bastante conhecida no debate alemão, depois de quase negligenciada até o final dos anos 1970. Isso me levou aos estudos weberianos, porque a minha experiência nos Estados Unidos e em Singapura reforçou esse interesse nos estudos comparativos. Considero a abordagem de Weber a mais promissora para entender o mundo em sua integridade, não apenas o mundo ocidental, mas o mundo ocidental em relação a todas as outras civilizações do mundo.

Além disso, começamos, quase simultaneamente com isso, a edição histórico-crítica das obras e das cartas de Weber [Max-Weber-Gesamtausgabe (MWG)], que dura mais de quarenta anos. Serão publicados 47 volumes [ 45 de textos e 2 de índices e registros] de escritos, discursos, cartas e anotações de aulas de Weber. É uma situação totalmente nova, porque o material está agora disponível para todos e é muito bom de ler. Portanto, a recepção limitada de Weber, que se restringe à tradução, não pode mais ser mantida em vista dessa riqueza de material que agora está disponível.

As traduções da obra de Weber

RW: Como você acha que essas publicações mudarão as interpretações weberianas?

Ws: A situação mudará lentamente, apenas lentamente, mesmo na Alemanha. Como ainda temos as edições antigas, os alunos as usam, já que são mais baratas que 
a nova edição. Então levará tempo. E o mais importante é que se precisa de novas traduções. A maioria das traduções disponíveis em outras línguas são felizes, mas outras são altamente confusas. Tivemos muitas conferências sobre essa questão, e é um problema muito interessante. Claro que toda tradução é uma interpretação, não existe uma tradução literal, mas é possível se desviar mais ou menos do original. $\mathrm{E}$ muitas vezes temos a situação em que a tradução em outras línguas é feita a partir da tradução do inglês, não da versão alemã. Então se tem, muitas vezes, a situação em que a tradução inglesa é usada para a tradução japonesa, que é usada para a tradução chinesa. É um telefone sem fio: começa-se com uma palavra e se termina com outra. Meu exemplo sempre é que se começa com "amor", termo central na nossa sociedade, e se vai do inglês para o japonês e depois para o chinês, e se termina com "sorte". Porque os chineses estão sempre procurando por sorte, não tanto por amor [risos]. Então, ocorre esse tipo de telefone sem fio.

Muitas vezes vejo como uma imagem distorcida de Weber é transmitida pela tradução, mas, devo enfatizar, não existe uma tradução literal, é sempre uma interpretação. Depende sempre do conhecimento do intérprete e do quão perto ele consegue se aproximar do original, e algumas vezes não é possível chegar próximo dele porque os termos não existem em outra língua. A linguagem de Weber é informada principalmente pelo debate jurídico da Alemanha, e muitos termos são da esfera legal, vinculados à tradição jurídica alemã, não sendo possível traduzi-los em outras línguas, o que torna necessário encontrar substitutos para isso. Mas, às vezes, isso leva a uma literatura de problemas que são produzidos por traduções.

Um exemplo interessante é a tradução de Talcott Parsons da "jaula de ferro" [iron cage]. Ela engendrou ampla literatura em torno da ideia da jaula de aço, mas é uma tradução equivocada do original, que não significa “jaula de ferro". Não que haja algo em uma jaula e outra coisa olhando de fora para ele, que quer sair da jaula! $\mathrm{O}$ argumento weberiano é que essas pessoas gostam de estar lá, elas querem estar aprisionadas, por assim dizer, nesse tipo de situação de vida em que estão colocadas. Possui uma conotação inteiramente diferente: é uma falta de interesse em transcender a ordem existente, estar satisfeito com essa ordem. E não é de ser aprisionado, no sentido de ser forçado externamente; quer-se estar ali. Gosta-se disso, de certa forma. Não se têm outros desejos que não estejam dentro da ordem existente. Essa é a ideia de Weber. Claro que ele não gosta disso, ele queria uma humanidade que ainda fosse capaz de transcender a ordem existente, de mudá-la e seguir adiante, mas a situação é tal que isso é interditado. Trata-se de uma noção que não é incorporada exatamente nessa tradução da "jaula de ferro", porém há toda uma literatura especializada sobre "a jaula de ferro". Até mesmo no livro de Arthur Mitzman, The iron cage, está no título! 
As diversas interpretações de Weber, de Parsons a Habermas

RW: Quão influente foi e ainda são, não só as traduções de Parsons, mas também a sua interpretação sobre Weber?

ws: Devo dizer que considero a interpretação de Weber feita por Parsons um êxito importante. Antes de tudo, ele traduziu A ética protestante e o espirito do capitalismo. Trata-se de uma boa tradução; tem algumas falhas, como a gaiola de ferro e provavelmente há outras, mas ainda é uma tradução muito boa. Ele fez um tremendo serviço à obra de Weber ao introduzi-la nos Estados Unidos. O primeiro texto traduzido para o inglês foi, curiosamente, o curso com palestras ministradas por Weber em 1919/1920 na Universidade de Munique, intitulado Wirtschaftsgeschichte [traduzido como General economic history]. Fora traduzido em 1927 por Frank Knight sem fornecer o capítulo de introdução, no qual os termos teóricos são desenvolvidos, o que é muito interessante. Ele deixou essa parte fora [risos]! Então foi recebido nos Estados Unidos como se não tivesse uma parte teórica na história. Weber estava muito interessado em fornecer o aparato conceitual para o estudo, mas isso foi negligenciado na tradução em inglês.

Parsons foi o primeiro que realmente introduziu Weber no mundo de língua inglesa com sua tradução de $A$ Ética protestante e do espirito do capitalismo e, posteriormente, com A. M. Henderson, com a tradução dos primeiros capítulos de Economia e sociedade, crucial. Sua interpretação na Estrutura da ação social [The structure of social action (1937)] também é bastante interessante, embora ele tenha usado Weber, é claro, como um bloco de construção de sua própria teoria. Portanto, ele não estava interessado em reconstruir Weber em seus próprios termos, ele queria usá-lo para seus próprios propósitos. E então temos esse debate sobre desparsonizar Weber, desparsonizar Durkheim e assim por diante.

É claro que esse esforço era necessário, de certa forma, para libertar Weber de uma interpretação parsoniana, mas, mesmo assim, Parsons fez um ótimo trabalho de introduzir Weber no mundo de língua inglesa. Foi uma maneira muito peculiar de se apropriar de sua herança. Portanto, após a Segunda Guerra Mundial, temos esse debate nos Estados Unidos. Entre Reinhardt Bendix, por um lado, e Parsons, por outro. Mas também Hans Gerth, Charles Wright Mills e assim por diante. Entretanto, e isto é crucial, ao contrário da Alemanha, nos Estados Unidos o debate não se centrou apenas na metodologia ou na posição política de Max Weber. Um debate sobre a sociologia da dominação, sobre a sociologia da religião, sobre estudos de classe e Estados. Portanto, era um modo muito mais amplo de recepção do trabalho de Weber em comparação com a Alemanha até as décadas de 1970 e 80 do século 
passado. Só então, na Alemanha, as pessoas perceberam que Weber era mais do que apenas metodologia e teoria política. Perceberam que existe uma rica proposta para análise comparativa. No centenário de seu nascimento (1964), houve uma convenção na Alemanha sobre Max Weber e a sociologia hoje [Max Weber und die Soziologie heute], que era o título da conferência, com a participação não apenas dos sociólogos alemães, mas também dos sociólogos internacionais. Estavam lá Parsons, Bendix, Benjamin Nelson, Marcuse, também pessoas da Itália e da França, como Pietro Rossi e Raymond Aron, respectivamente. Ficou claro que o entendimento de Weber era muito mais amplo fora da Alemanha. Os alemães ainda estavam brigando entre a teoria crítica e o positivismo, e negligenciavam a gama enorme do aparato conceitual fornecido pelos estudos comparativos e da Economia e sociedade de Weber.

Portanto, havia um desequilíbrio entre a recepção de Weber fora da Alemanha e dentro da Alemanha, embora ele seja um autor alemão. Eu argumentaria que só mais tarde a Alemanha alcançou o debate internacional e depois assumiu a liderança. Eu diria que, agora, a Alemanha assumiu a liderança. Não apenas por causa da edição histórico-crítica [MWG], mas também porque muitas das monografias mais interessantes foram escritas a partir da abordagem de Weber, considerada um empreendimento intelectual ainda muito viável e amplo. Mas o cenário não era esse logo após o fim da Segunda Guerra Mundial. Weber não era considerado essencial na história intelectual alemã.

RW: Como você vê o impacto de sua própria interpretação nesse contexto? Afinal, muitos intelectuais, como Jürgen Habermas, reconbecem que você trouxe contribuiçôes e interpretações completamente novas, mesmo na Alemanha.

WS: Aprecio esta interpretação [risos], mas não tenho tanta certeza da importância do impacto. No caso de Habermas, é verdade, houve um curto período em que trabalhamos muito juntos e tínhamos o plano de fazê-lo a longo prazo. Infelizmente não se materializou, em parte porque decidi não me juntar ao seu grupo em Starnberg [no Max-Planck-Institut]. Portanto, nós nos separamos novamente, após um período de intensa troca. E ele usou de fato especialmente a sociologia da religião no primeiro volume do livro da sua teoria da ação comunicativa. Ele tem uma abordagem diferente de Weber, porque ele argumentava o tempo todo que, em seu livro, Weber era muito interessante no trabalho substantivo, mas sua teoria sobre o afeto era muito limitada, apesar de ter o potencial de melhorar a partir do seu trabalho substantivo. Mas Habermas, na teoria da ação comunicativa, mudará totalmente a atitude da Escola de Frankfurt em relação a Weber. Antes disso, Weber era considerado pelos membros da Escola de Frankfurt como um positivista ou o que quer que fosse, algo 
que teria sido superado e que não deveria interessar muito; Habermas mudou essa percepção com o primeiro volume da Teoria da ação comunicativa.

Tive a sorte de ter meu livro, publicado em 1979, The rise of Western rationalism, traduzido pelo meu bom amigo Guenther Roth para o inglês, caso contrário não teria nenhum impacto. Se causou ou não impacto, não sei; mas sinto prazer de ouvir em sua pergunta que provavelmente é o caso. É sempre bom ouvir isso, mas não tenho conhecimento real de até que ponto isso vai. Mostra novamente que apenas quando as coisas são traduzidas para o inglês são recebidas em todo o mundo; caso contrário, os trabalhos alemães não são recebidos fora da Alemanha.

\section{A leitura de Schluchter: a história desenvolvimental}

RW: Existem muitos aspectos importantes em sua interpretação, mas há um que se destaca: a tese de que há, na obra de Weber, uma história desenvolvimental [developmental history em inglês; Entwicklungsgeschichte em alemão], que implica o tema da evolução. Qual é, exatamente, o significado da ideia de evolução em Weber?

ws: Comecei com uma comparação de duas abordagens possíveis para Weber. Uma era a ideia de Johann Winckelmann, que apontava para um tipo de fenomenologia da história universal, na qual se colocam as coisas lado a lado, em pé de igualdade. A outra era de Friedrich Tenbruck, um importante autor alemão. Sua interpretação de Max Weber foi evolucionista, mas não estava tão claro o que evolução significava em sua abordagem. A teoria evolucionista estava muito em debate naqueles tempos, a partir disso ele considerava Weber um evolucionista. Portanto, há posições muito opostas uma à outra: a história universal fenomenológica, por um lado, e a teoria evolutiva, por outro, tendo o Ocidente como o cume da espécie humana.

Argumentei que nenhuma dessas posições é viável. Precisamos de algo entre elas, e o que pode ser considerado e colocado entre as duas posições é o que chamei de história desenvolvimental, uma história do desenvolvimento do Ocidente. Existem outras histórias desenvolvimentais, não apenas do Ocidente, e elas não podem ser consideradas superiores ou deficitárias. Trata-se de um dispositivo heurístico para analisar a história do mundo de uma perspectiva europeia, sem implicar um sentido normativo, de que a Europa seja superior a outras civilizações. É uma tentativa de encontrar a particularidade do desenvolvimento ocidental em comparação com outros desenvolvimentos. Portanto, a história do desenvolvimento não é a fenomenologia da história universal, nem a teoria da evolução no sentido tradicional do termo, como na teoria evolutiva de Charles Darwin. É a análise peculiar de um desenvolvimento único, no qual se está interessado. Visa a descobrir como somente 
no Ocidente surgiram coisas que poderiam ter sido possíveis em outras civilizações, embora não tenham se desenvolvido por lá. Mas isso não quer dizer que, por ter se desenvolvido aqui, sejam superiores a todo o resto do mundo. Só se está interessado na reconstrução de sua própria história e se precisa de outra civilização como uma espécie de fólio para entender por que seu desenvolvimento é distinto dos outros desenvolvimentos.

Então, tentei enfatizar essa noção de história desenvolvimental, que é também um dispositivo metodológico no trabalho de Rickert, tratando da diferença entre a mera mudança, por um lado, e a teoria evolutiva, no sentido de uma noção normativa da evolução, por outro. E ele argumenta que a história desenvolvimental é uma noção condicional-teleológica de desenvolvimento. E fui convencido de que a abordagem do próprio Weber pode ser reconstruída nesses termos. É uma abordagem eurocêntrica - sempre afirmei que é uma abordagem eurocêntrica -, mas é heurística, não normativa. Claro que Weber tem clara a questão de que somente no Ocidente emergiram coisas que têm significação universal e provavelmente (provavelmente!) validade. A significação é clara: o capitalismo é algo muito significativo para a humanidade, assim como a ciência moderna. Ninguém no mundo hoje pode evitar os princípios da ciência moderna - na Índia, na China, aonde quer que se vá, encontra-se a ciência moderna com o mesmo tipo de estrutura em todas essas civilizações. Então houve algo inventado no Ocidente que penetrou no mundo. Isso não quer dizer que o Ocidente seja a mais alta civilização no mundo e que todas as outras são deficitárias.

\section{Racionalização, desencantamento do mundo e secularização}

Ws: Nós voltaremos a isso quando falarmos de Shmuel Eisenstadt, porque Eisenstadt começou sua ideia de modernidades múltiplas exatamente com base na ideia weberiana de multiplicidade de histórias desenvolvimentais, ou seja, de que há muitas histórias desenvolvimentais e que cada civilização tem seu próprio modo de lidar com esses desafios que o mundo ocidental produziu a partir dos anos 1500 em diante, começando com os períodos das descobertas, depois com a Renascença, a Reforma, o Iluminismo. Isso mudou o mundo, mas não unificou o mundo. $\mathrm{O}$ mundo é muito diferente em suas variadas formas por causa de tradições culturais que podem lidar com esses desafios introduzidos pelo Ocidente, em parte pacificamente, mas também em parte pela força (como o imperialismo e colonialismo etc.). Portanto, essa era a ideia da história desenvolvimental, algo que é mais da fenomenologia do mundo da história universal e menos do que uma teoria evolutiva no sentido estrito do termo. 
RW: Podemos dizer que a racionalidade é a força motriz dessa evolução?

ws: Claro. Um dos argumentos de Weber é que a racionalização é um processo que pode ser detectado em todas as civilizações, mas em diferentes formas de civilização. Os estudos comparativos na sociologia da religião nos forneceram diferentes tipos de racionalidade. Ele sustenta que os estudos comparativos são uma contribuição à sociologia e à tipologia do racionalismo. E essa é uma de suas ideias muito interessantes. Ao contrário da crítica da religião que encontramos no jovem Karl Marx e em Ludwig Feuerbach, Weber argumenta que religião e racionalidade nem sempre são poderes contrários. A religião é uma força para desenvolver a racionalidade. E não está confinado à tradição judaico-cristã; temos o mesmo no budismo, temos o mesmo, em certa extensão, no confucionismo. $\mathrm{O}$ resultado são diferentes tipos de racionalidade, ou seja, a maneira como as pessoas se relacionam com o mundo e como interpretam sua própria vida. Não é uma hierarquia estritamente falando entre esses vários tipos de racionalidade. A tipologia e a sociologia do racionalismo são o propósito desses estudos comparativos. É claro que também devemos encontrar a particularidade da trajetória ocidental. Esse era o seu interesse, que acredito ser bem sintetizado na seguinte pergunta: como é que no Ocidente temos esse desenvolvimento peculiar, um desenvolvimento que não é apenas significativo para outras civilizações, mas também, em certa medida, válido, que deve ser retomado? Mas é sempre em mistura com suas próprias tradições.

E acho que é isso que Eisenstadt sempre teve em mente quando tentou reinventar essa ideia de multiplicidade. Ele chama de modernidades múltiplas - não gosto do termo, porque ou é "modernidade múltipla" ou "modernidades". Ele diz que são múltiplas modernidades, mas tudo bem, isso não é importante. Sua ideia era que não pode haver uniformidade na maneira como as novas invenções são apropriadas, porque sempre existe uma tradição cultural que tem uma forte resistência ou uma fraca resistência a essas imposições externas. E, portanto, resulta em uma multiplicidade de modernidades e não apenas uma modernidade.

$\mathrm{RW}$ : Então a ideia de Eisenstadt das modernidades múltiplas, em sua visão, éconsistente com a abordagem de Weber?

ws: Sim, até certo ponto. Quero dizer, o problema com a abordagem de Eisenstadt, na minha opinião, é que, conceitualmente, não há uma formulação rigorosa tal como é característico na própria abordagem de Weber. E ele sempre me dizia: "Fatos? Eu não ligo para fatos!” [risos]. Mas, em certo sentido, ele faz uma boa tentativa. Ele tentou continuar essa ideia que encontramos nos estudos comparativos da socio- 
logia da religião. Ele fez isso com seus próprios meios, mas em uma relação muito próxima com a abordagem weberiana. Eu nem sempre estava de acordo com ele, tínhamos longas conversas. Trabalhamos juntos por quase cinco anos; ele era um bom amigo meu e passamos bons momentos juntos, mas não aceitei tudo que ele estava tentando fazer. Mas acho que alguém poderia dizer que tentei continuar esse programa em novos termos. E, até certo ponto, ele aceitou minha interpretação da ascensão do racionalismo ocidental, sempre citou este livro, mas não leu muito dos meus trabalhos posteriores [risos].

RW: Retomando o que falamos sobre racionalismo e religião, gostaria de perguntar sobre a conexão entre racionalidade, desencantamento do mundo e secularismo.

Ws: Antes de tudo, eu argumentaria que secularização é um termo que Weber usa de vez em quando, mas não com muita frequência. É usado principalmente no ensaio sobre as seitas religiosas nos Estados Unidos, no qual ele afirma que as associações são uma forma secular da seita. Lá ele usa o termo secularização. Mas não usa o termo da maneira como é normalmente usado atualmente, como a transição de uma religião para uma visão de mundo secular. Para esse caso ele usa o termo desencantamento do mundo. Faço uma distinção clara entre o desencantamento do mundo e a secularização. Nos últimos tempos, voltei-me, em certa medida, ao livro de Charles Taylor, The Secular Age. Lá, Taylor distingue três tipos de secularização, e é bem claro, afirmei isso antes: é possível colocá-la no nível das visões de mundo, para referir-se a uma visão de mundo secular ou à visão de mundo religiosa; ou então se relaciona com os padrões institucionais, nos quais se intensifica a separação entre Estado e igreja, mas também o fato de o Estado ter prioridade sobre a igreja; finalmente, é possível relacioná-la com o nível individual, para afirmar que as pessoas têm crenças religiosas ou não, são seculares ou têm uma mente religiosa. Taylor apresentou, em minha opinião, um argumento crucial, do qual gosto e que assumi. Ou seja, a distinção entre aquilo que ele chama de "quadro": há um quadro transcendental, ou religioso, e um imanente, ou secular.

Tivemos um debate na Alemanha nos anos 1960, início dos anos 70, quanto à noção filosófica de secularização. Havia uma posição sustentada por Karl Löwith, Carl Schmitt e outros, segundo a qual o mundo moderno é o resultado de uma secularização da religião no termo mais amplo de convicções religiosas e visões de mundo religiosas. Por outro lado, havia Hans Blumenberg, que argumentava que a secularização é um conceito errado, porque nega a legitimidade dos tempos modernos. Porque se argumenta que a modernidade é o resultado da secularização, argumenta-se que algo estava lá e foi transformado em outra coisa, mas ainda depen- 
de do que era antes, então se nega a legitimação do novo elemento que surge com a transição da visão de mundo religiosa para a secular.

$\mathrm{Na}$ minha opinião, Taylor tem um bom argumento, porque ele diz que isso não significa o desaparecimento da religião, mas se trata de uma situação diferente para a religião, ela se torna uma opção. Numa visão de mundo religiosa, a religião não é uma opção, é preciso ser religioso, não se pode nem mudar de uma religião para outra sem estar em perigo de ser expulso da sociedade e arruinar sua existência. Nos tempos modernos, a religião se torna uma opção: pode-se ser religioso, pode-se mudar de uma religião para outra, de uma confissão para outra, ou negar ser religioso, e isso é algo muito novo. Esse argumento sustenta que a religião não desaparecerá, mas que a posição da religião dentro de todo o tecido da sociedade mudou totalmente ao tornar-se uma opção. É nisso que consiste a modernidade. É o que Weber tinha em mente quando falava sobre o desencantamento do mundo. $\mathrm{O}$ desencantamento do mundo é uma situação em que a religião se torna uma opção; essa é a minha interpretação. Portanto, não é secularização. É preciso distinguir entre secularização e desencantamento do mundo. E, ao contrário da leitura de Taylor, o desencantamento do mundo para Weber não é um processo que se inicia no século XV ou XVI, mas um processo de longo alcance que se inicia no judaísmo antigo. Portanto, é uma interpretação diferente do processo no caso de Weber. Gosto dessa ideia de que o desencantamento do mundo, como Taylor afirma, é uma indicação dessa transição de um quadro transcendental para um quadro imanente. E a situação diferente da religião dentro do quadro imanente, porque no quadro imanente ainda se pode ser religioso, e pode lutar pela religião, que é um elemento que transcende o mundo, do imanente à transcendência. Mas é apenas uma opção entre outras opções, e a questão é se se trata de uma opção melhor ou pior, algo que se precisa decidir por si mesmo.

Nesse contexto, imediatamente se percebe que o fundamentalismo é uma rebelião contra essa ideia de que a religião é uma opção, porque ao argumentar que a religião é uma opção se relativiza seu credo religioso. Quero dizer, pode-se acreditar pessoalmente que é a coisa certa a se fazer e na qual acreditar. Mas, estritamente falando, não se pode argumentar que é o único que sabe o que é verdade. Há um elemento de relativização nesta noção de opção, e o fundamentalismo se opõe a isso: só pode haver uma única verdade. Se é um protestante, o catolicismo deve ser considerado como algo falso. Não é uma alternativa, é falso. A postura fundamentalista não implica apenas um retorno às fontes, uma leitura literal dos escritos, mas a ideia de que essa é a única verdade que conta, enquanto o resto é deficitário comparado a ela. Considero o fundamentalismo como a oposição da ideia da religião como uma opção. 
RW: Você considera ofundamentalismo outra patologia da modernidade ou outra forma de expressar a religião?

ws: Considero uma patologia da modernidade, mas realizada com meios modernos. A posição em si é questionar o caráter opcional da religião, que é negado.

RW: Então o fundamentalismo não é compativel com a ideia de pós-secular?

ws: Eu não gosto da palavra “pós-secular”, pois não é pós-secular, é secular. Secular dentro de um enquadramento secular: ainda existe a religião e a religião é uma opção, não há dúvida sobre isso. Faz muito sentido argumentar que se quer transcender sua vida imanente e dar significado a ela. Precisa-se de algo para além da vida existente, e a religião é uma oferta para essa relação com algo além, maior que a própria existência. Então a religião será sempre um pano de fundo viável para os humanos enquanto eles procurarem pelo sentido, mas não é a única forma. Há muitas pessoas que não aceitam a interpretação religiosa da transcendência. Elas querem outros modos de transcendência, modos seculares de transcendência, algo muito difícil de se atingir, mas, mesmo assim, temos agora a situação em que viver sem a religião tem a mesma dignidade que viver com religião. E isso não era verdade no século xv, lá não havia uma opção, em que se podia ser religioso ou não religioso: era preciso ser o membro de um grupo religioso.

RW: Você considera que Weber previu essa permanência da religião, mesmo que nas margens?

ws: Sim, claro! No final de A Ética protestante e o espirito do capitalismo, há essa afirmação muito famosa: "quem sabe o que aparecerá no futuro: ou uma revitalização das grandes religiões ou novos ideais que não conhecemos no momento, novas grandes ideias".

RW: Isso é interessante, trata-se quase da mesma conclusão de Durkheim em As formas elementares da vida religiosa, em que o autor formula um questionamento sobre o que vai acontecer, ainda que seja por razóes diferentes.

Ws: Embora, estritamente falando, Durkheim seja mais secular do que Weber, porque seu argumento é que a moralidade e a religião civil que a acompanha são basicamente seculares. Não tem mais comandantes religiosos, mas é produto da efervescência coletiva. E é mais do que o individualismo, leva o individualismo para além das limitações como indivíduo, mas é algo em si secular. 
RW: No caso da abordagem weberiana, poderiamos afirmar que a continuidade das religiōes no mundo contemporâneo, mesmo no fundamentalismo religioso, tem a ver com essa suposição básica de Weber de que os seres humanos precisam buscar sentido?

ws: Com certeza! Não há vida humana sem a tentativa de dar sentido à própria vida. Não se trata somente de uma necessidade externa que experienciamos muito frequentemente, em que as pessoas precisam de recursos, mas também há sempre uma necessidade interna, e é preciso resolver a necessidade interna. Os seres humanos buscam sentido, uma interpretação da vida, e, portanto, a religião nunca desaparecerá. Eu nunca li Weber deste modo, como se dissesse que a religião vai desaparecer. Porém, ela passou a ter um estatuto diferente sob as condições modernas em comparação com o que tinha no passado, e é muito importante para um entendimento correto da constituição política, já que o Estado, de acordo com Weber, goza de prioridade sobre todas as outras instituições que, por sua vez, são produtoras e supridoras de sentido. O Estado em si não é uma instituição provedora de sentido, é um fórum, sob o qual se podem ter diferentes atitudes, em que a religião tem um papel, a convicção não religiosa tem um papel, mas devem ser tratadas como iguais em relação a seu acesso para o Estado. O Estado Moderno é o fórum sob o qual se tem essa possibilidade de opções para resolver o problema do sentido. O Estado em si não deve resolver o problema do sentido, é só o enquadramento formal sob o qual se pode resolver o problema do sentido. Assim, o Estado não é a encarnação do sentido, mas um instrumento que permite a multiplicidade e a pluralidade de iniciativas de produção e de busca de sentido. Essa é a separação do Estado e Igreja, mas não só isso, a separação do Estado e qualquer tipo de ideologia.

RW: E o que acontece quando a religiäo não está satisfeita em estar em sua própria esfera e deseja interferir na vida política? Essa é uma tendência geral, não apenas do ponto de vista do Islä, mas também de muitas seçôes do protestantismo no Brasil.

ws: Sim, mas penso que temos que rejeitar isso.

RW: Então essa é sua posição normativa quanto à relação entre religião e Estado?

ws: Sim, essa é a minha posição normativa, e digo que é a consequência do quadro imanente que temos agora. Estamos vivendo em uma estrutura imanente, não na estrutura transcendental. A estrutura transcendental é uma opção, mas não deve ser definida como a forma em que podemos viver. E essa é a razão pela qual não 
podemos aceitar uma leitura fundamentalista do Islã, no qual a lei sagrada é considerada como seria a secular. Nossa lei é secular, e o sistema legal é a estrutura na qual podemos executar nosso interesse diferente em buscar e produzir sentido. Mas não é ele próprio o fornecedor desse significado, é apenas um fórum. O que chamamos de estado neutro. Essa é uma posição anti-hegeliana, é claro, é também uma posição antidurkheimiana. Porque Durkheim ainda tem a ideia de que o Estado tem um elemento que pode ser considerado sagrado, que é mais do que simplesmente um instrumento, cujas diferentes tendências dentro da religião ou dentro das visões de mundo são organizadas e mediadas entre si. E nenhum movimento único pode tentar conquistar o Estado.

RW: A civilização ocidental tem esse princípio fundamental; mas como pensar a questão em outros países, baseados em diferentes relações entre o Estado e a religião? De que modo isso é um problema ou desafio para Weber?

Ws: Concordo que temos esses dois modelos, por assim dizer. Ainda temos civilizações onde o transcendente é primordial, e não o quadro imanente. Mas, na minha opinião, o que pode surgir, com argumentos muito bons, é que o quadro imanente é algo que não pode mais ser descartado. Está no mundo, e, mesmo nessas sociedades que não o aceitam no momento, haverá mudança a longo prazo nessa situação e o quadro imanente penetrará no mundo inteiro.

RW: Os Estados Islâmicos, por exemplo, vão passar por um processo de secularização?

ws: Absolutamente. A longo prazo, acho que não há outro caminho. Quero dizer, será uma luta interna. Hoje em dia não se pode aceitar uma teocracia. Como podemos aceitar uma teocracia? Não podemos argumentar que é o mesmo nível do nosso sistema democrático altamente diferenciado. Quero dizer, uma teocracia é uma instituição pré-moderna. A esse respeito, sou totalmente normativo. Estou discutindo de maneira normativa. Considero a transição para o quadro imanente como algo realizável e que não pode mais ser perdido.

RW: Portanto, não éapenas um processo necessário, mas também um processo desejado?

Ws: Na minha opinião também é um processo desejável. É um processo que ocorreu e, portanto, está no mundo e nunca mais desaparecerá. Não consigo conceber uma situação em que isso desapareça. Mas pessoalmente considero uma situação desejável, na qual temos um estado neutro e temos uma multiplicidade de instituições e mo- 
vimentos buscando sentido e fornecendo sentido e pessoas que tentam dar sentido à sua vida. Em relação à religião ou à crença não religiosa.

RW: Realizamos muitas coisas com a modernidade; por outro lado, isso não traz um tipo de desafio? Por exemplo, instituimos não apenas a possibilidade, mas também a necessidade de ser livre. Uma pessoa que vive em um mundo não moderno, em que o estado não é secular, sem ter que escolher uma religião, não teria como contrapartida algum tipo de vida mais feliz?

ws: Sim, isso pode ser verdade. Não sei. Minha suspeita seria que, a longo prazo, mesmo que já se tenha uma teocracia em alguns desses países islâmicos, a busca por interpretações opcionais de sentido prevalecerá a longo prazo. Habermas já teve um argumento muito bom, a meu ver, muito perspicaz: não se pode não aprender [risos]. Quer dizer, se você teve um insight, ele não desaparecerá mais, você não pode voltar para uma situação em que esse insight desaparece para sempre. Não se pode não aprender. E é por isso que gosto tanto do Iluminismo, porque você sabe que viu a luz e não pode voltar para a escuridão.

Penso, ainda, que um dos principais problemas da era secular, na qual estamos vivendo no momento, pelo menos no mundo ocidental, é encontrar essa transcendência do imanente. Na era "religiosa", o problema era mediar as forças transcendentais no imanente, da existência humana. Precisava-se de Jesus para tornar Deus uma entidade acessível. Para tornar a ordem abstrata, eterna, aceitável para os seres humanos, precisa-se de personalizações do poder transcendental abstrato. Agora, na ordem imanente, há o problema de encontrar recursos para ir além do dado e transcender o mundo imanente. Portanto, a religião continua sendo uma força crucial. Nunca aceitei essa ideia de que a religião desaparecerá. Ela mudou de posição dentro do tecido da existência humana. Não pode mais reivindicar ser uma solução final para tudo, para algumas pessoas pode ser verdade, para outras não. Mesmo aceitando, não podem agir de tal maneira que descarte todas as outras possibilidades, estão sempre no horizonte. Isso nunca desaparecerá.

RW: Weber estava preocupado com of fato de que na modernidade as pessoas de alguma forma perderiam esse horizonte de sentido. Ele tentou identificar isso na religião, mas chegou a considerar que poderiamos encontrar significado nas formas de arte e erotismo etc. Ele estava convencido de que poderiamos encontrar sentido fora da religião ou a religião seria o único lugar em que podemos encontrar sentido?

Ws: Ele próprio, como pessoa, não tinha um ouvido musical para a religião, não que 
ele rejeitasse a religião, mas ele não tinha a atitude interior para se tornar religioso, uma pessoa religiosa. Era incapaz de viver tal existência. Então Weber tentou dar sentido à sua própria vida em termos não religiosos. E é assim que muitas pessoas hoje em dia vivem. Elas tentam dar sentido à sua vida fora da religião. E isso é possível, provavelmente instável, mas possível.

RW: Não é uma forma sólida.

Ws: Não é sólida. Ela vem sendo ampliada com certas restrições, mas ainda é uma alternativa: a autodeterminação. Weber era definitivamente alguém que se considerava uma pessoa autodeterminada e não confiava em nenhum credo religioso. Às vezes se tem a sensação de que é um tipo de atitude heroica, uma atitude que precisa de tremenda força interior, para ser vivida. E sempre há esse problema de como guiar sua vida e como morrer. Porque isso é certo, que se vai morrer.

RW: No sentido de como se podem encontrar os demônios que guiarão sua vida, quais demônios se devem servir.

ws: Sim, é isso que Weber chama de demônio. Demônio significa seu próprio destino, aquele que se escolheu. E aqui o ponto decisivo é a escolha.

RW: Nesse sentido, somos livres, mas isso também é um fardo.

ws: Absolutamente, é um fardo tremendo. É muito fácil viver em uma constelação onde o problema é resolvido. Na modernidade se tem que resolver sozinho. A propósito, essa é uma diferença interessante com Nietzsche, porque Weber sempre desconfiou da ilusão de Nietzsche do problema do homem moderno, ou seja, o além-homem [Übermensch]. Isso é uma nova ideologia, de acordo com Weber. Nietzsche não é capaz de manter essa posição muito precária, na qual não se tem mais base de segurança, é preciso produzi-la por conta própria. E Nietzsche teve a solução final: o além-homem. Essa é uma nova religião, mas não é uma boa religião, porque não tem os pontos fortes das religiões tradicionais; mas é, no entanto, uma nova religião. Weber desprezava isso, ele não queria isso. É preciso produzir o significado da sua vida. É uma escolha! Isso é crucial, é uma escolha. Não é apenas uma escolha como se escolhe entre Coca-Cola e Sprite, é uma escolha existencial. E a escolha existencial tem consequências para toda a sua vida.

Sobre isso ser relativismo ou absolutismo, nesse sentido, Weber argumenta que esses valores têm uma demanda absoluta na existência humana. Quando se está na 
esfera ética, existe uma demanda absoluta para agir de acordo com esses princípios éticos. Quando se está na esfera erótica e se apaixona, não há escolha; então, se é atraído por essa esfera. E é um compromisso absoluto.

RW: Se está servindo outro deus.

ws: Sim, e aí se está de fato servindo outro deus. Isso é o que Weber chamou de batalha dos deuses, e esses deuses estão lutando entre si. Querem ter supremacia sobre o indivíduo, qualquer um quer que seja seu discípulo. Há uma batalha entre eles, mas se se serve a um deus, não pode servir ao mesmo tempo a outro, e é assim que funciona em todas as esferas de valor e as ordens de vida. Existe esse conflito entre esses deuses que lutam, e isso também estava em Ciência como vocação, em que esses deuses gregos antigos estão novamente à nossa volta como poderes impessoais, não como deuses personalizados como no mundo grego, mas como poderes impessoais, valores abstratos. O grau de autonomia entre as esferas aumentou em comparação com o que tínhamos antes. Esse é o sentimento da sua vida. É preciso resolver esses conflitos o tempo todo. Normalmente se fazem concessões, mas se se é realmente sério, não há concessões. É preciso escolher entre um ou outro.

\section{A racionalização como o motor da história}

$\mathrm{RW}$ : Nessa concepção, portanto, a razão e a racionalização são a força motriz.

ws: São a força motriz, mas Weber é muito claro sobre isso: a racionalização produz potências contrárias o tempo todo. O que é considerado de um ponto de vista como racional pode ser considerado de outro ponto de vista como irracional, não racional. Aplica-se a todos esses conceitos duais, nos quais ele tenta expressar diferentes dimensões da racionalidade, como racionalidade instrumental, racionalidade com relação a valor, racionalidade formal e substancial, racionalidade teórica e prática.

Esses são elementos em que ele tenta mostrar que não há uma reconciliação entre diferentes formas de racionalidade, há sempre uma antinomia, um conflito entre elas. E se avança com a racionalidade formal, então sempre haverá um contra-argumento de que o resultado deve ser sustentado por um ponto de vista substancial e, assim, ser tomado como algo não aceitável. As forças de produção podem ser desenvolvidas no capitalismo até um ponto extremo, mas o resultado pode ser que a distribuição de renda seja injusta; então se avalia isso de um ponto de vista racional-substancial, de um ponto de vista de valor, pensando que "bom, isso é injusto, não quero ter esse resultado, então é preciso mudar". A racionalidade é sempre dupla, uma vai para tal 
direção, a outra para a outra, e não há reconciliação entre as formas de racionalidade: é sempre essa ideia de antinomia.

Especialmente nos últimos capítulos de Economia e sociedade de 1919-1920, Weber enfatiza a relação entre economia e dominação, entre racionalidade formal e substantiva. A racionalidade do procedimento leva a resultados que, de um ponto de vista racional substantivo, são considerados inaceitáveis e irracionais. Essa é uma de suas convicções e também tem algo a ver com a teoria do valor, de que sempre há um conflito entre elas. Não há reconciliação, sempre há conflitos, antinomias. Há paradoxos, e não reconciliação.

RW: Há espaço para a emoção?

ws: Há espaço para emoção, definitivamente. Há espaço para a emoção nos Conceitos sociológicos fundamentais, quando Weber enfatiza a ação afetiva na relação entre ela e a ação racional com relação a valor. $O$ racional com relação a valor está profundamente enraizado nas emoções, ao contrário da ação racional instrumental, que é um distanciamento das emoções. Elementos emocionais são relacionados a nossas identidades, com o sentido subjetivo que atribuímos à nossa vida. Isso sempre tem elementos afetivos e racionais com relação a valor.

RW: Nesse sentido, o valornão é apenas um elemento cognitivo, mas também emocional.

ws: Exato. Na Consideração intermediária [Zwischenbetrachtung], Weber discutiu a relação entre uma ética de convicção de fraternidade e todas as outras esferas da vida, como economia, política, ciência. Além destas duas esferas de valores a-racionais: arte e erótica, e elas não são racionais, ele chama a ética de convicção de fraternidade de a-racional; elas não podem ser racionalizadas da mesma maneira que o poder e a utilidade.

É possível reconstruir a Consideração intermediária levando sempre em conta que a racionalidade é um conceito multidimensional, no qual se encontram tendências contrárias. Nunca há uma fácil reconciliação de diferentes tipos de racionalidade. A racionalidade instrumental e a racionalidade com relação a valor são, até certo ponto, opostas uma à outra; se pode ser uma ou outra.

RW: Qual é a diferença entre eles, o Zweck [Fim] e o Wert [Valor]?

Ws: A diferença é definida como uma ação racional instrumental [Zweck] orientada para o sucesso. Já na relação com um valor [Wert], a ação é orientada para a realização de um valor por si só. 
Um valor ético pode ser, nos termos kantianos, um dever ético por si só, realizado mesmo que contra suas inclinações. Não porque se ganha algo com isso, não porque se torna bem-sucedido ao executá-lo, pois mesmo que falhe, ele tem seu valor em si. Essa é a definição nos Conceitos sociológicos fundamentais. A ação racional instrumental é uma ação orientada para o sucesso. Quero ter sucesso e, portanto, preciso entender a relação entre meios e fins, preciso de um sinal de reconhecimento para isso, e quanto mais tiver, melhor. Portanto, vou perceber o que devo fazer e ser bem-sucedido e, se falhar, não são necessárias sanções. Durkheim distingue entre regras técnicas e morais: a regra técnica é aquela que não precisa de uma sanção, porque violou seu próprio interesse. Em casos morais, é preciso uma sanção, porque o ato e a consequência da ação não estão conectados analiticamente, como ele diz, mas sinteticamente. É preciso uma instância intermediária para conectar os dois. Deriva de Kant, é claro, a distinção dos imperativos categóricos e hipotéticos. Tanto no caso durkheimiano, quanto no weberiano.

A maneira como Durkheim usa Kant é diferente da maneira como Weber usa Kant, porque Durkheim transforma Kant em sociologia, enquanto Weber mantém Kant separado da sociologia. Por isso argumentei que em Durkheim a sociologia é um kantismo sociológico, enquanto a sociologia de Weber é uma sociologia kantiana. Isso faz diferença. O kantismo sociológico é a transformação de Kant em sociologia, ou seja, Durkheim e a sociologia kantiana mantêm a ideia de Kant separada da análise sociológica empírica, mas usa-a como guia para uma distinção que pode ser usada no nível da análise empírica. E é a distinção entre racionalidade valorativa e racionalidade instrumental. Racionalidade valorativa significa que se faz isso por si só, independentemente do sucesso, enquanto na outra é feito apenas em relação ao sucesso; caso contrário, não o faz. Caso se saiba que não se terá sucesso, não se executa uma ação racional instrumental.

RW: Háliberdade de escolha do objetivo quando se trata de um Zweck [fim], mas não quando se está na esfera do Wert [valor]?

ws: Bem, você tem um ponto muito bom aqui. Essa é uma questão terminológica; as palavras em alemão são Wert e $Z$ weck, que significam valor e fim, o que soa um tanto estranho. Portanto, reformulei isso um pouco, argumentando que Weber define fim como o sucesso que se torna a causa de uma ação, e valor como a validade que se torna a causa de uma ação. Então faz sentido dizer que a antecipação de um sucesso se torna a causa da ação: isso seria a racionalidade instrumental; e a validade, a noção de validade, se torna a causa de uma ação: isso é racionalidade valorativa. Então tentei reformular esses dois conceitos de valor e fim, que seriam a tradução 
literal de Wert e Zweck, porque não há uma ação sem um propósito. Esse é o duplo sentido de teleológico: uma ação é sempre teleológica num sentido geral, porque é sempre em termos causais entre fins e meios, de um jeito ou de outro, sempre.

As noções de valor de Weber são muito mais amplas, não se limitam à ética; também há estética, e, em seguida, ele chama alguns valores de valores culturais, que são relativos a uma determinada cultura. Quanto à ética, acho que ele a considera em sentido kantiano, como distinta dos valores culturais, mas essa é uma questão muito complicada que precisa de mais elaboração do que normalmente é o caso em relação à posição de valor de Weber. Minha solução para esse problema, para esse complicado problema conceitual, é simplesmente dizer: fim é a antecipação ou a noção de um sucesso, que se torna a causa de uma ação; e o valor é a noção de uma validade, seja uma validade ética, validade moral, validade religiosa ou o que quer que seja, não importa, é sempre o mesmo tipo de causa de ação: fazer algo por si só.

RW: Isso é crucial para entender a reflexão weberiana, porque temos a ideia de que toda ação precisa de um fim, o que faz pensar que elas são iguais, mas na verdade elas não são as mesmas.

Ws: Sim, elas não são as mesmas. Essa é uma mistura dessas duas noções de teleológico, porque a ação é sempre teleológica. E há um teleológico especial, que é o instrumental, e o outro, que é com relação a valores. Mas ambos são teleológicos no sentido geral, a ação é sempre teleológica.

A importância da teoria e a prática do sociólogo

RW: Qual a importância da teoria para a sociologia?

Ws: Construção de teoria ou formação de conceito, por um lado, e aplicação, por outro, são importantes. Portanto, sempre há essa relação entre o lado teórico e o empírico. A teoria serve à análise empírica.

RW: Portanto, essa poderia ser uma diferença básica entre teoria social e filosofia.

Ws: Sim, mas não vejo as fronteiras entre as disciplinas tão estritamente definidas. Não são disciplinas, são problemas. O problema está no centro, não a disciplina. Um problema não se importa com as distinções disciplinares. Um problema é um problema, deve-se resolvê-lo; e, para isso, ou se têm meios conceituais adequados ou não. E se não tiver meios conceituais adequados, não poderá resolver o problema. 
Portanto, é sempre essa interação entre teoria e realidade. Análise da realidade, que eu acho crucial. Seja teoria social, teoria sociológica ou filosofia, não importa. A única coisa que realmente considero importante é a distinção entre teoria e ontologia social. Mas essa é uma história diferente, que tem a ver com problemas de emergência e com a noção de Durkheim de sociedade como algo sui generis. A sociedade existe em um nível ontológico ou não? No caso de Durkheim, há uma tendência em seus escritos metodológicos de considerá-la em um nível ontológico: a realidade social existe em um nível ontológico. Penso que Weber discorda disso. Existem propriedades emergentes, são propriedades, não confirmações ontológicas. Agregação, por exemplo. Transformação por meio de agregação, de relações sociais, que se tornam cada vez mais independentes do indivíduo, quanto maior a ordem. O estado é independente do que você está fazendo e do que estou fazendo, mas não é independente de todos. Mas ele não considera isso um nível ontológico.

RW: Durkheim muda suas premissas ontológicas após 1905. Ele precisava dessas premissas para enfrentar o debate interno francês.

ws: Concordo. Em Durkheim, há discrepância entre suas declarações metodológicas e a maneira como ele realiza suas pesquisas. E há uma tendência a uma interpretação diferente dessa relação.

RW: As regras do método sociológico são, talvez, a parte mais frágil da sua obra, estão absolutamente enraizadas no debate interno da época.

ws: Concordo plenamente.

RW: Pelo menos no Brasil durante muito tempo a parte metodológica de Durkheim foi a mais conhecida; talvez um dos motivos de ter sido desconsiderado como autor relevante.

Ws: É sempre importante distinguir entre o que o autor diz sobre o que ele faz e o que ele realmente faz [risos].

Rw: O que Durkheim faz é completamente diferente do que ele afirma que devemos fazer como sociólogos.

Ws: Sim. 
A biografia de Weber

RW: Há quantas biografias sobre a vida de Weber?

ws: Temos agora três. O primeiro foi Joachim Radkau, a biografia de Radkau que está traduzida também em espanhol, como acabei de descobrir. E em inglês também, é incrível! É um livro ruim [risos]. Quero dizer, ele até cria interesse, é claro, porque tem essa característica que, em alemão, chamamos de Schlüssellochperspektive, ou seja, olha para a intimidade da vida de Weber, para sua vida sexual. Mas não fala muito sobre o trabalho em si, e realmente não nos fornece uma boa interpretação da maneira como Weber lidou com sua doença, com seus problemas, como os superou. É incrível como esse homem estava realmente deprimido, a tal ponto que considerou seriamente cometer suicídio. E sobreviveu, sobreviveu de maneira impressionante. E esse é o ponto interessante, e não se recebe essa resposta no livro dele sobre esse assunto.

RW: Quais seriam as causas das doenças de Weber?

ws: Não está bem claro. A doença fazia parte de sua constituição fisiológica e não temos nenhum documento que nos permita fazer um julgamento final sobre essa doença. Conhecemos os sintomas, conhecemos as consequências. Isso é o que hoje em dia é chamado de transtorno bipolar. Há momentos em que ele é muito ativo, superprodutivo e, em seguida, há períodos em que está totalmente deprimido e precisa de todos os tipos de drogas para sobreviver e conseguir dormir. Os médicos prescreveram medicamentos que hoje consideramos perigosos. E então ele teve que ficar um tempo longe do trabalho e tudo mais. Portanto, é uma espécie de alternância entre excitação, produção excessiva e depressão. Ele passou por um tratamento tradicional, naqueles tempos o tratamento era fisiológico basicamente, não psicológico. Karl Jaspers era um amigo muito próximo de Weber, médico e psiquiatra, sugeriu a pessoas como Weber uma autoanálise. Ele deveria se sentar e escrever. E Weber escreveu uma autoanálise, mas infelizmente Marianne destruiu a autoanálise no período nazista. Ela queria evitar a possibilidade de que fosse descoberto e usado contra Max Weber. Infelizmente, não sabemos muito sobre as causas reais. Existe uma correspondência entre Marianne Weber e sua mãe. Elas discutem a situação de Max Weber durante esse período, de 1898 a 1902. Elas trocam ideias sobre o motivo, mas é tudo especulação, é realmente especulação.

RW: E houve alguma influência da sua doença em suas obras? 
ws: Não é uma influência direta. É indireta, definitivamente. Por exemplo, A ética protestante e o espirito do capitalismo é uma análise do ascetismo intramundano em relação com a profissão. Weber estava interessado em encontrar essa relação porque a experimentou ele mesmo, essa é a minha interpretação; experimentou o colapso total em relação às suas capacidades profissionais. Então, ele queria entender quais são as condiçôes culturais em que as pessoas agem como os protestantes ascéticos. Weber pensou: "eu mesmo fui um protestante ascético por alguns anos, minha carreira foi fulminante, tive um tremendo sucesso, fiquei sobrecarregado e de repente desmoronei. Qual é o significado disso?". Quando se vive em uma constelação onde apenas importa ser bem-sucedido em sua profissão, mas, de repente, não pode mais trabalhar. Essa é uma experiência que desperta o interesse em um assunto como esse. Esse é pelo menos um motivo que pode ser atribuído à seleção deste tópico de A ética protestante e o espirito do capitalismo, mas é apenas um, entre muitos outros.

Portanto, não vejo uma relação direta entre sua história pessoal e o trabalho como outras pessoas viram, como Arthur Mitzman, que argumentou que Weber matou seu pai para possuir sua mãe. Houve uma situação familiar em que Weber defendeu sua mãe contra seu pai. O pai era um patriarca, ele era realmente obsessivo em manter sua esposa perto de si, como serva sua. Ela tinha o dinheiro, e ele usou o dinheiro e assim por diante. E a mãe era muito próxima de Marianne Weber, esposa de Max Weber. E também, é claro, para Max, ela era uma mãe muito amorosa. Sempre preocupada com o desenvolvimento de seu filho, o filho mais velho. E houve uma situação em que o pai foi buscar a mãe para levá-la de volta a Berlim, e Weber, em uma intensa discussão com o pai, o expulsa da casa e mantém a mãe lá. O pai foi embora e morreu três semanas depois, sem reconciliação com o filho e sem reconciliação com a mãe. As pessoas argumentam que esta é uma situação freudiana [risos]. Então ele sentiu uma forte culpa, e essa foi a razão pela qual ele teve a doença. Esse foi o argumento de Mitzman e, em seguida, ele argumentou que, para superar essa culpa, Weber estudou A ética protestante e o espirito do capitalismo, o asceticismo intramundano. É preciso superar a culpa, e só é possível fazê-lo vivendo uma vida disciplinar, expulsando todas as emoções. Esse é o argumento de Mitzman: por isso Weber teria escrito $A$ ética protestante e o espirito do capitalismo com ênfase no asceticismo intramundano. Mas então começa a amar Elsa Jaffé e mais tarde Mina Tobler, e de repente ele descobre o misticismo [risos]. Amor!

RW: Era um relacionamento platônico ou eles realmente tiveram um caso?

ws: Não, eles tiveram um caso mais tarde, mas só mais tarde. Foi platônico durante esse primeiro período, quando Alfred Weber já havia iniciado um relacionamento 
amoroso com Elsa. Max tinha um profundo amor por Elsa, mas ela era sua aluna. Ele não se permitiu levar adiante. Ele suprimiu até certo ponto. Então, só mais tarde, em 1917, iniciou um relacionamento amoroso com Elsa.

RW: E a Marianne sabia disso?

ws: Sim, ela estava ciente. Marianne sabia, apesar de tentarem esconder.

$\mathrm{RW}$ : Mas isso não era um problema para ela?

Ws: Não sabemos, emocionalmente provavelmente foi um problema. Mas ela até mesmo apoiou o relacionamento.

RW: Por quê?

ws: Ninguém sabe... talvez porque ela queria vê-lo feliz. Ela era uma amiga muito próxima de Elsa também, era um relacionamento próximo entre as duas.

RW: Mas ela sabia que mesmo quando Weber estava, digamos, apaixonado por Elsa, mesmo não tendo um caso com ela, Marianne sabia?

Ws: Sim, ela percebeu em 1911. Houve uma situação em que eles estavam todos juntos e Max pegou flores para ela, para Elsa. E Marianne percebeu que ele estava apaixonado por ela. Ele devia estar apaixonado por ela. Eles estavam juntos e Marianne percebeu que era um amor profundo de sua parte. Ele não levou adiante, ficou escondido, mas o amor estava lá, e ela sabia disso. Mais tarde, quando Weber teve que decidir se iria ou não a Munique, ela teve a decisão final sobre ir ou não, e Marianne escolheu por irem porque Elsa morava perto de Munique. Ela decidiu isso. E existe uma carta muito comovente, imediatamente após a morte de Weber, na qual Marianne escreve para Elsa que sabia sobre o caso, é uma carta muito emocionante e muito interessante.

RW: E Weber nunca pensou em se divorciar de Marianne?

ws: Não, nunca. Ele gostava muito dela, tinha muito orgulho dela, porque era uma mulher muito emancipada, e ele também era grato pelo apoio que ela lhe deu durante sua doença, ele não teria sobrevivido a esse período sem ela. Ele sempre reconheceu isso e chegou mesmo a afirmar: "eu não teria sobrevivido sem Marianne”, nesse 
período entre 1898 e 1902. E há um conflito. É um conflito. E, por outro lado, ele aceitou o fato de que não se pode fazer nada contra o relacionamento emocional.

$\mathrm{RW}:$ É quase a salvação trazida pela paixão, é o mesmo sentimento.

ws: Tem um valor em si. E mesmo que isso seja contrário às nossas convençóes, mesmo aos nossos mandamentos éticos, não se pode fazer nada contra esse relacionamento emocional. É um relacionamento emocional e tem sua própria legislação.

RW: Épor isso que na Consideração intermediária ele afirma que o amor compete com a religião na possibilidade de salvação?

ws: Sim, ehá cartas em que ele discute a Consideração intermediária com Elsa. Weber mudou o texto na $20^{\mathrm{a}}$ versão em comparação com a $15^{\mathrm{a}}$ versão até certo ponto. Foi em virtude de sua relação com a esfera erótica ter mudado até certo ponto, e ele discute isso com Elsa. E este é o argumento: a esfera erótica tem uma legislação própria e é contrária a mandamentos éticos, não há como resolver o conflito entre os dois. Ou se tem que sacrificar seu amor ou tem que sacrificar o compromisso ético, mas não se pode ter os dois. Seria um desastre argumentar - esta é a posição de Weber - que a ética é a única coisa que conta no mundo. Também há emoção, e o relacionamento pessoal entre dois amantes é algo que possui um elemento sagrado.

RW: Está além da sua escolha, não se pode escolher quem se ama.

ws: É certamente algo que escapa à nossa escolha. Não se pode escolher.

RW: Pode-se escolher com quem permanecer casado, como companheiro, mas não quem ama.

ws: Claro. Porque o casamento não é necessariamente baseado no amor. E esse casamento não se baseava no amor desde o começo. Provavelmente para Marianne foi amor, mas não para Max. Primeiro, provavelmente era um tipo de relacionamento instrumental, mas depois cresceu muito e se tornou um relacionamento realmente sério, que Weber reconheceu no primeiro volume dos ensaios sobre a sociologia da religião. Eles viveram juntos, e o sentimento cresceu em uma dimensão diferente em relação a esse amor existencial que ocorre na esfera erótica.

$\mathrm{RW}$ : É uma tensão interna. 
ws: Sim, Weber viveu em tremenda tensão. Por um lado, havia seu trabalho. Ele tinha esse dever de trabalhar, de produzir sua obra. Ele foi capaz de separar as coisas uma da outra. Quando ele trabalhava, todo o resto estava fora. Mas há o outro lado. Esse sentimento permanente de não pertencer. Desde o seu primeiro colapso Weber sentia não pertencer aos saudáveis. Esse é o sentimento básico de sua vida: "Eu não pertenço”. E não se encontra isso nessas biografias.

RW: Para ele, o trabalho era algum tipo de fuga?

ws: Sim, era provavelmente uma maneira de escapar desses conflitos internos. Mas também era um tipo de obsessão, ele tinha que trabalhar.

RW: Essa foi sua maneira de encontrar um sentido para sua vida...

ws: Sim, mas acho que Weber nunca identificou claramente desse modo.

Referências Bibliográficas

\section{Outras entrevistas com Wolfgang Schluchter}

De Moraes, Paulo; Tufano, Sara \& Neri, Hugo. (2014), “O estabelecimento de um programa de pesquisa weberiano: entrevista com Wolfgang Schluchter”. Revista Plural, São Paulo, 21 (1): 231-246.

Do Valle, Ulisses; Da Silva, Luiz; Fallone, Rafael; Lopes, Hober; Pereira, Fernanda \& Quinta Júnior, Elbio. (dez. 2013), “Entrevista com o Prof. Dr. Wolfgang Schluchter: realizada em 18 de setembro de 2013”. Revista de Teoria da História, Goiânia, 5 (10):292-300.

Marinis, Pablo. (2008), "Max Weber: la disputada herencia de un clásico de la sociologia: entrevistas a Wolfgang Schluchter y Dirk Käsler”. Revista Española de Investigaciones Sociológicas, Madri, 121: 169-192.

NeutZling, Inácio. (2005), “Novos conceitos em permanente gestação: entrevista com Wolfgang Schluchter”. Cadernos IHU em formação, São Leopoldo, 3: 33-36.

Valarini, Elizangela. (dez. 2018), "Entrevista com Prof. Dr. rer. pol., Dr. h.c. Wolfgang Schluchter: O pensamento de Max Weber na Sociologia contemporânea”. Em Tese, Florianópolis, 15 (2): 221-234.

Villas BoAs, Glaucia. (2011), "A atualidade de Max Weber: entrevista com Wolfgang Schluchter”. Sociologia e Antropologia, Rio de Janeiro, 1 (1): 11-20. 
WeIss, Raquel. (2017), "Talking theory with Wolfgang Schluchter". (25m55s). Disponível em https://youtu.be/t-fi7h0oZR8, consultado em 15 maio 2020.

Texto recebido em 18/7/2020 e aprovado em 18/9/2020.

DOI: 10.11606/0103-2070.ts.2021.172568.

Raquel Andrade Weiss é professora titular no Programa de Pós-Graduação em Sociologia na Universidade Federal do Rio Grande do Sul (UfRGS). E-mail: weiss.raquel@gmail.com. Carlos Augusto Silva Fabris é mestrando no Programa de Pós-Graduação em Sociologia na Universidade Federal do Rio Grande do Sul (UfRGS). E-mail: carlos.fabris8@gmail.com. 